\title{
Development of an Ointment Formulation Using Hot-Melt Extrusion Technology
}

\author{
Ajinkya M. Bhagurkar, ${ }^{1}$ Muralikrishnan Angamuthu, ${ }^{1}$ Hemlata Patil, ${ }^{1}$ Roshan V. Tiwari, ${ }^{1}$ Abhijeet Maurya, ${ }^{1}$ \\ Seyed Meysam Hashemnejad, ${ }^{2}$ Santanu Kundu, ${ }^{2}$ S. Narasimha Murthy, ${ }^{1}$ and Michael A. Repka ${ }^{1,3,4}$
}

Received 21 August 2015; accepted 12 November 2015; published online 1 December 2015

\begin{abstract}
Ointments are generally prepared either by fusion or by levigation methods. The current study proposes the use of hot-melt extrusion (HME) processing for the preparation of a polyethylene glycol base ointment. Lidocaine was used as a model drug. A modified screw design was used in this process, and parameters such as feeding rate, barrel temperature, and screw speed were optimized to obtain a uniform product. The product characteristics were compared with an ointment of similar composition prepared by conventional fusion method. The rheological properties, drug release profile, and texture characteristics of the hot-melt extruded product were similar to the conventionally prepared product. This study demonstrates a novel application of the hotmelt extrusion process in the manufacturing of topical semi-solids.
\end{abstract}

KEY WORDS: hot-melt extrusion; lidocaine; ointment; PEG; texture analyzer.

\section{INTRODUCTION}

In the pharmaceutical industry, ointments are manufactured by melting oil and aqueous phases in two separate jacketed vessels with agitators for proper mixing. The two phases are transferred to the main ointment vessel through valves and pipes. The additional stirrers in the main vessel provide agitation (1). During the entire course of operation, uniform mixture of all the components (base+drug) is crucial. Formation of agglomerates and non-uniform distribution of drug in the base are the potential challenges encountered owing to inefficient mixing and improper design of the mixer. The content is not uniformly mixed in the dead spots of the vessel. Thus, additional steps are required for recirculation to avoid wastage of product accumulated at the dead spots (2).

Hot-melt extrusion (HME) is an established technology in the plastic, rubber, and food industries. Since the past few decades, this technique is known as a successful continuous and solvent-free process. Recently, this technology is under investigation for application in pharmaceutical research and industry. In HME process, rotating screws drive the physical mixture (drug+inactive excipients) above the glass transition temperature

\footnotetext{
$\overline{{ }^{1} \text { Department of Pharmaceutics and Drug Delivery, School of Phar- }}$ macy, The University of Mississippi, University, Mississippi 38677, USA.

${ }^{2}$ Dave C. Swalm School of Chemical Engineering, Mississippi State University, Oktibbeha County, Mississippi 39762, USA.

${ }^{3}$ Pii Center for Pharmaceutical Technology, School of Pharmacy, The University of Mississippi, University, Mississippi 38677, USA.

${ }^{4}$ To whom correspondence should be addressed. (e-mail: marepka@olemiss.edu)
}

(Tg) and/or above the melting temperature $(\mathrm{Tm})$ based on the type of material used in the formulation. Thus, uniform mixing of active pharmaceutical ingredient and thermoplastic binders, polymers, or both is achieved (3). Thus, HME technology is used to formulate granules, pellets, immediate and controlled release tablets, and transdermal and transmucosal drug delivery systems (4-6). HME, a proven manufacturing process, complies with the goal of US FDA process analytical technology (PAT) scheme for designing, analyzing, and controlling the manufacturing process (7). It improves the quality and efficacy of the manufactured products, and hence, it is being explored for numerous pharmaceutical applications (7). In this study, we investigated a new application of HME technology in the field of production of topical semi-solids. HME provides many advantages over conventional methods of ointment preparation, such as reduced processing time since melting of the ingredients and mixing is a one-step process. Moreover, no additional agitators and scrapers are required since mixing action is performed by the screw elements in the barrel. The screw elements also aid in particle size reduction. Additionally, the processing parameters could be customized to obtain products with desired characteristics.

Lidocaine (melting point: $68^{\circ} \mathrm{C}$ ) was used as a model drug. It is crystalline in nature and has a pKa of 7.8 (8). Lidocaine acts as a local anesthetic by blocking the fast voltage-gated sodium channels in the cell membrane of postsynaptic neurons, thus preventing depolarization and inhibiting the generation and propagation of nerve impulses (9). Lidocaine ointment is used as an anesthetic for accessible mucous membranes of the oropharynx, as an anesthetic lubricant for intubation, and for temporary pain relief associated with minor burns (10). In this study, polyethylene glycol (PEG) was selected as the base for the ointment. The PEG 


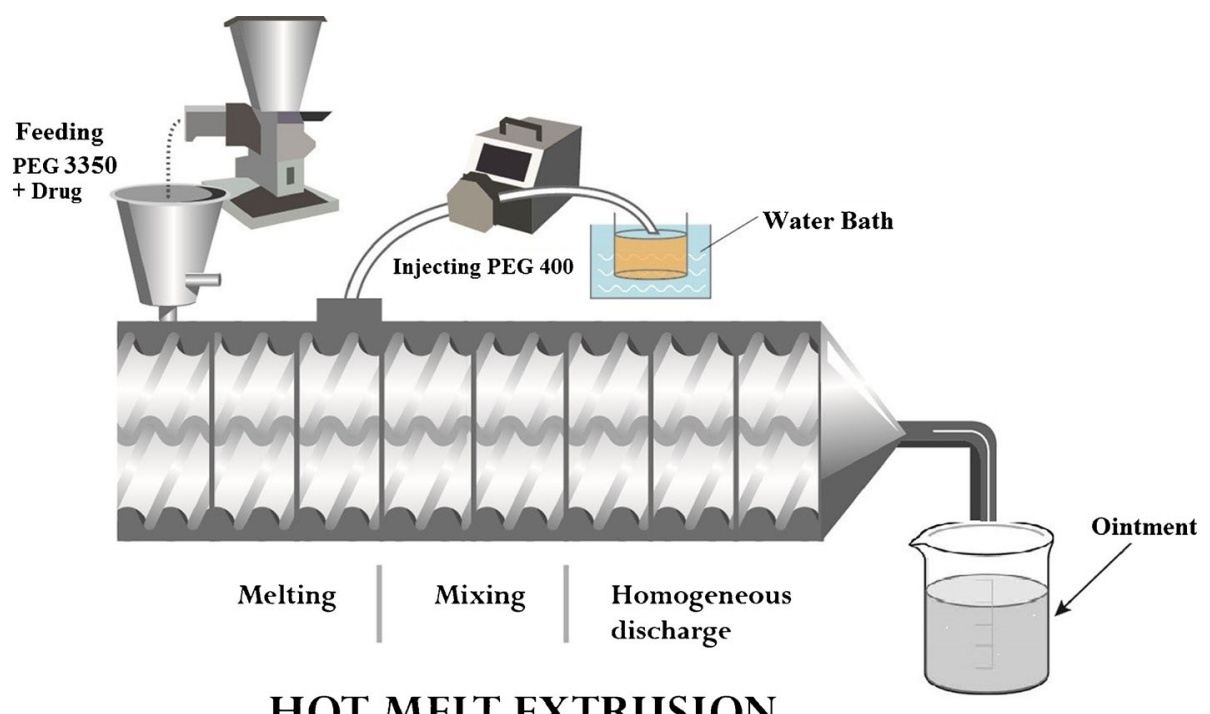

Fig. 1. Schematic representation of preparation of ointment by hot-melt extrusion technology

bases are water soluble, washable, possess good spreadability, and are stable (11). The ointment base composition of $50 \% \mathrm{w} /$ $w$ PEG 3350 and $50 \% w / w$ PEG 400 was selected, since this combination is recommended in the USP.

The main objective of this study was to investigate the potential use of the HME process in the continuous manufacturing of topical semi-solid products. Therefore, the characteristics of the product prepared by HME were compared with that of a reference product prepared by the fusion method.
MATERIALS AND METHODS

\section{Materials}

Lidocaine USP was purchased from Spectrum Chemical Mfg. Corp. (New Brunswick NJ, USA). Polyethylene glycol 3350 was purchased from Electron Microscopy Sciences (Hatfield PA, USA); Carbowax ${ }^{\circledR}$ PEG 400 NF was

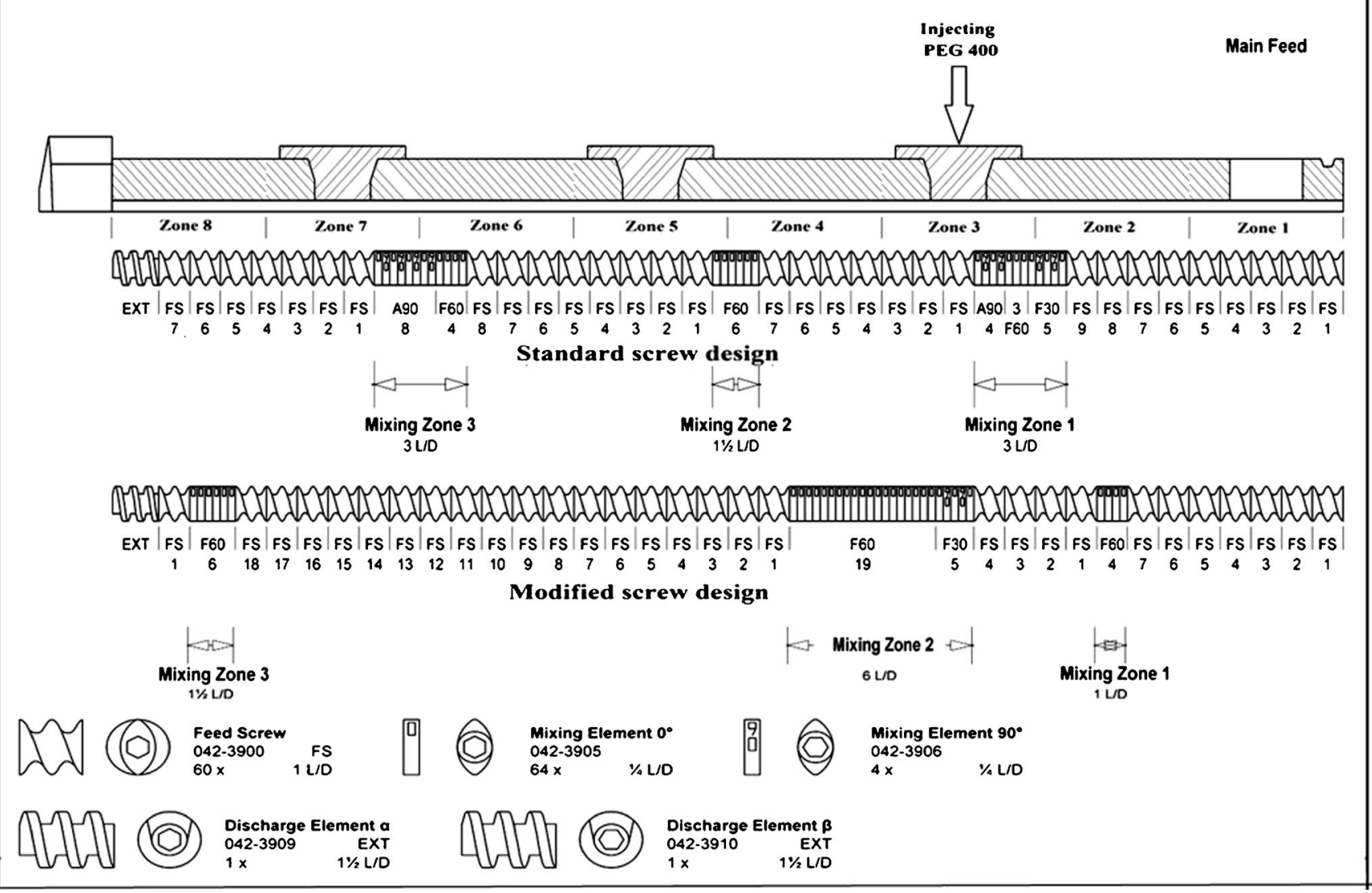

Fig. 2. Modified screw design used for the preparation of an ointment 
purchased from Fischer Scientific (NJ, USA). All other chemicals used were of analytical grade.

\section{Preparation Methods}

\section{Preparation of Ointment Formulation}

Conventional Ointment. The conventional method of fusion was used for the preparation of ointment. Mixture of lidocaine, PEG 3350, and PEG 400 was melted on a hot plate by heating it to $75^{\circ} \mathrm{C}$. The mixture was then removed from the hot plate and was stirred continuously until it congealed (11).

Hot-Melt Extruded Ointment. A schematic illustration of preparation of ointment by HME is shown in Fig. 1. Lidocaine base was blended with PEG 3350 at drug loading of $5 \% w / w$. This binary mixture was fed into a corotating twin-screw extruder (11 $\mathrm{mm}$ Process $11^{\mathrm{TM}}$, ThermoFischer Scientific, Karlsruhe, Germany) with a volumetric feeder. PEG 400 was introduced in the extruder barrel in zone 3 , through an injection port using a peristaltic pump. The screw speed was set at $200 \mathrm{rpm}$, and the barrel temperature was set to $75^{\circ} \mathrm{C}$ in the first five zones and $40^{\circ} \mathrm{C}$ in the remaining zones. A modified screw design as shown in Fig. 2, with 3 mixing zones, was used for extrusion $(12,13)$. The composition of the ointments is shown in Table I.

\section{Characterization of Raw Materials and Formulations}

Differential Scanning Calorimetry. Physical characterization of lidocaine, PEG 3350 (melting range $53-57^{\circ} \mathrm{C}$ ), and the ointment formulations was assessed using differential scanning calorimetry (DSC; Diamond DSC, Perkin Elmer) equipped with Pyris manager software. Samples of around 2-4 mg each were weighed and sealed in aluminum pans and analyzed at a heating rate of $10^{\circ} \mathrm{C} / \mathrm{min}$ under an inert nitrogen atmosphere at a flow rate of $20 \mathrm{~mL} / \mathrm{min}$, over a temperature range of $30-150^{\circ} \mathrm{C}(14)$.

$X$-ray Diffraction. X-ray diffractograms were acquired for ointment formulations prepared using HME and conventional techniques. The studies were performed using SmartLab3 X-ray diffraction system (Rigaku, Japan) equipped with HyPix-400 2-D detector and SmartLab Studio II® software. Samples were filled into a glass sample holder and exposed to $\mathrm{CuK} \alpha$ radiation $(40 \mathrm{kV} \times 4 \mathrm{~mA})$ to collect diffractogram over $2 \theta$ range of 4 to $40^{\circ}$ with an increment of 0.0114 at $1 \mathrm{~s}$ per step.

\section{pH Measurement}

Weighed amount of ointment was dissolved in water so as to get final ointment concentrations of $1 \% w / v, 5 \% w / v$, and $10 \% w / v . \mathrm{pH}$ of these solutions was measured using the Mettler Toledo InLab®Micro $\mathrm{pH}$ probe (Electrolyte $3 \mathrm{~mol} / \mathrm{L}$ $\mathrm{KCl})$.
Table I. Composition of the Ointment Formulations

\begin{tabular}{lll}
\hline $\begin{array}{l}\text { Method } \\
\text { of preparation }\end{array}$ & $\begin{array}{c}\text { Lidocaine } \\
(\% w / w)\end{array}$ & $\begin{array}{c}\text { Ointment base } \\
\text { composition }(\% w / w)\end{array}$ \\
\hline $\begin{array}{l}\text { 1.) Hot-melt } \\
\text { extrusion }\end{array}$ & $5 \%$ & $\begin{array}{c}50 \% \text { PEG } 400+50 \% \\
\text { PEG 3350 }\end{array}$ \\
\begin{tabular}{l} 
2.) Conventional \\
\hline
\end{tabular} & $5 \%$ & $50 \%$ PEG $400+50 \%$ PEG 3350 \\
\hline
\end{tabular}

\section{Uniformity of Drug Content}

Predetermined amount of ointment formulation was taken from three different regions of an ointment jar and was dissolved in methanol. The samples were then subjected to centrifugal filtration. The supernatant was collected and directly injected into high performance liquid chromatography (HPLC) to measure the drug content.

\section{Method of Analysis}

The lidocaine content was analyzed using Waters HPLCUV (Waters Corp) system. A Luna C18 Phenomenex column with dimensions of $250 \times 4.6 \mathrm{~mm}(5 \mu)$ was used for this study. The mobile phase used was methanol and $25 \mathrm{mM}$ dibasic potassium phosphate $(80: 20 \% v / v)$ and the flow rate was adjusted to $1 \mathrm{~mL} / \mathrm{min}$. The injection volume was $20 \mu \mathrm{L}$ and detection wavelength was $220 \mathrm{~nm}$. The retention time of lidocaine was found to be $5.9 \mathrm{~min}$. A calibration curve $\left(R^{2}=0.999\right)$ was plotted after measuring the peak areas of the standard solutions of lidocaine. Drug concentration in the samples was determined by measuring the peak area of sample and comparing it with the peak area of the calibration curve (15).

\section{Texture Profile Analysis of Ointment Formulation}

Texture Analyzer model TA.XT2i (Texture Technologies Corp. /Stable Micro Systems) along with a 1-in. diameter (TA3), acrylic, cylindrical probe, and a soft matter kit (TA-275) was used for the determination of texture properties. The various set parameters for texture analysis are shown in Table II.

Table II. The Various Set Parameters for Texture Analysis

\begin{tabular}{ll}
\hline Parameter & Set value \\
\hline Test mode & Compression \\
Pre-test speed & $0.50 \mathrm{~mm} / \mathrm{s}$ \\
Test speed & $0.50 \mathrm{~mm} / \mathrm{s}$ \\
Post-test speed & $5.00 \mathrm{~mm} / \mathrm{s}$ \\
Target mode & Distance \\
Distance & $1 \mathrm{~mm}$ \\
Trigger type & Auto \\
Trigger force & $5.0 \mathrm{~g}$ \\
Hold time & $5.00 \mathrm{~s}$ \\
Advanced options & Off \\
Temperature & Room temperature
\end{tabular}




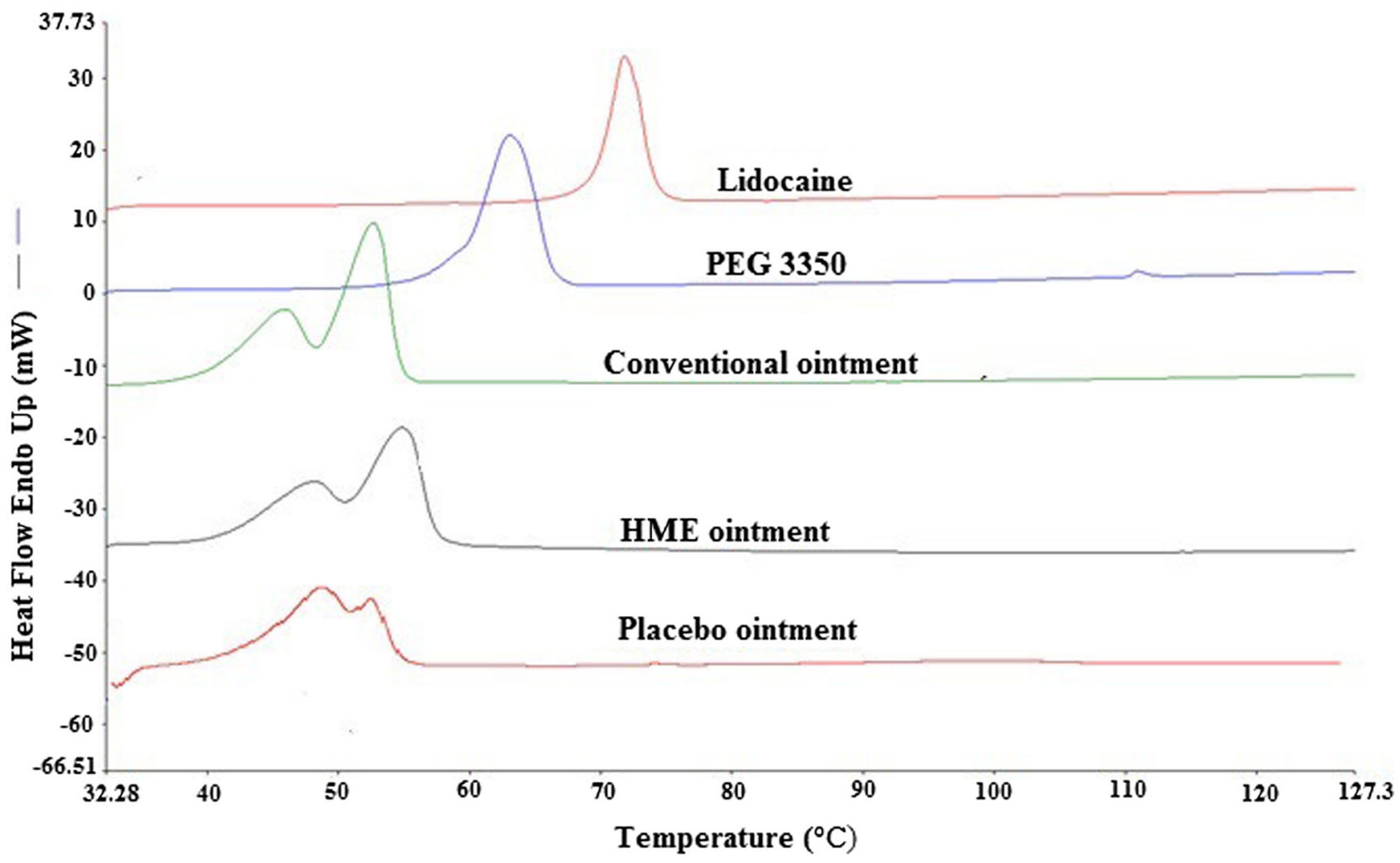

Fig. 3. DSC thermogram of lidocaine, PEG 3350, and different ointment formulations

Soft matter fixture was filled with the product, and it was placed below the texture analyzer's probe. The test was performed by lowering the probe at the pre-test speed to the product surface. The probe produced an additional deformation of $1 \mathrm{~mm}$ of the sample at the test speed of $0.50 \mathrm{~mm} / \mathrm{s}$ after coming in contact with the surface and sensing the trigger force. The probe then withdrew from the sample at the speed of $5.00 \mathrm{~mm} / \mathrm{s}$.
The same procedure was repeated for other samples after cleaning the probe and leveling the surface of the sample (16).

\section{Rheological Characterization}

Rheological measurements were performed using TA instrument HR-2 rheometer. All experiments were conducted

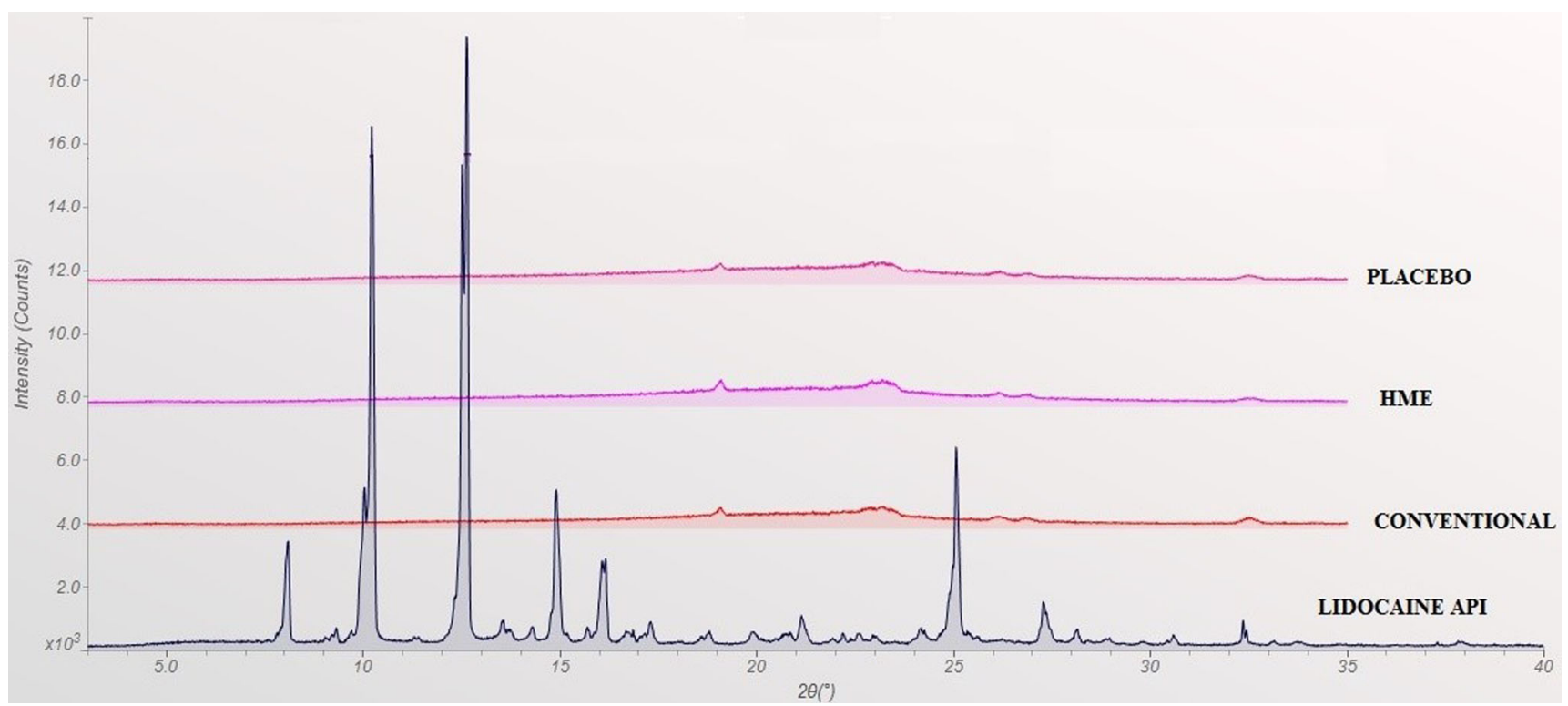

Fig. 4. XRD data for the drug, conventional and HME formulation 


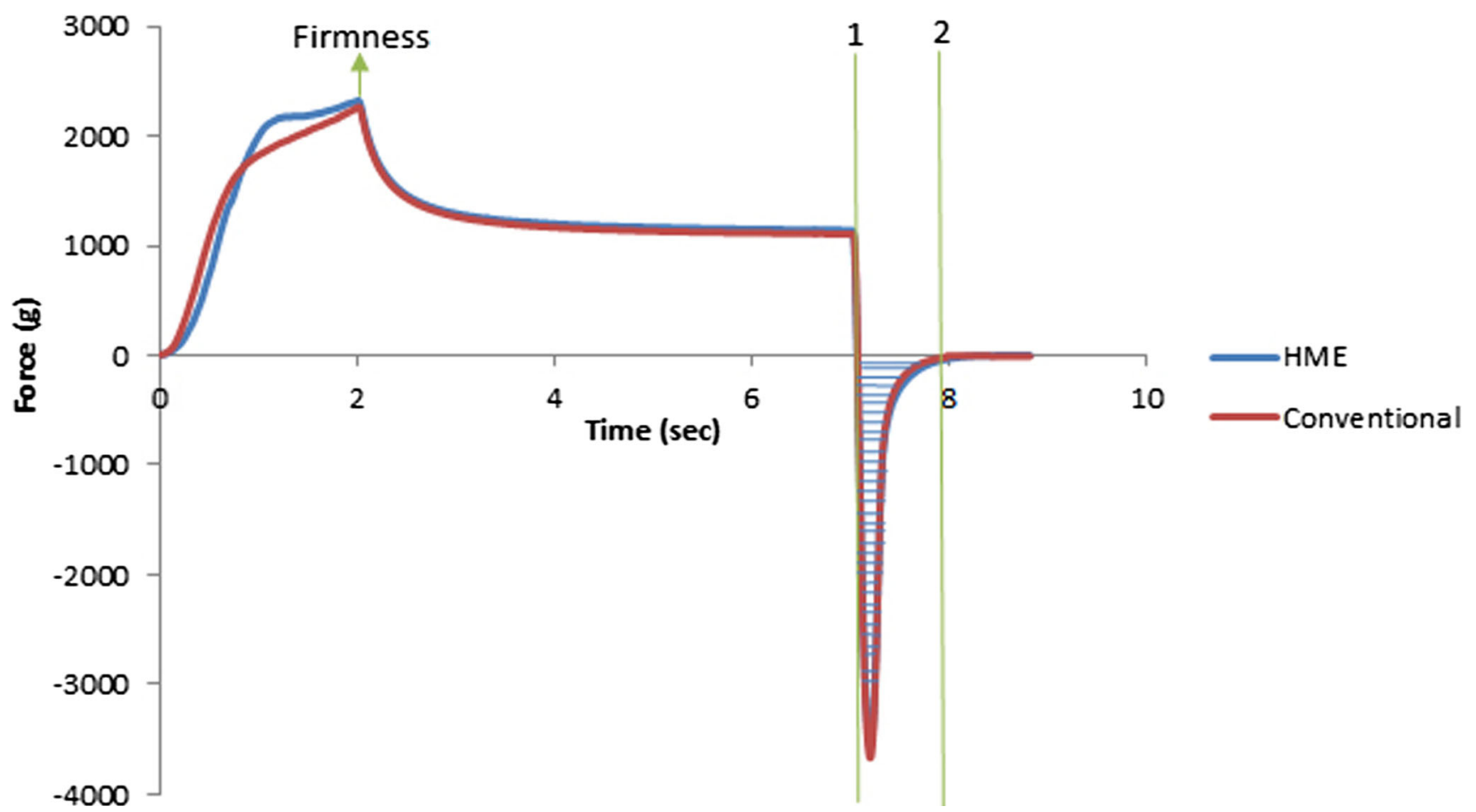

Fig. 5. Representative picture of data of texture analysis of lidocaine ointments

at room temperature $\left(22^{\circ} \mathrm{C}\right)$ and using $25 \mathrm{~mm}$ parallel plate geometry. Adhesive backed sand papers (grit \# 600 provided by Allied High Tech Products Inc.) were used for upper and lower plate in order to reduce slippage at the sample-plate interface. For each test, approximately $400 \mathrm{mg}$ of sample was placed on the lower plate followed by slowly adjusting the upper plate to reach to a gap of $550 \mu \mathrm{m}$. After trimming off excess sample, the gap was set at $500 \mu \mathrm{m}$ for rheological testing. Rheological characterization included four steps performed in sequence for each sample. Time sweep (at strain, $\gamma_{0}$, of $0.1 \%$ and frequency, $\omega$, of $1 \mathrm{~Hz}$ ) was conducted for 10 min to allow the sample to relax the stress the sample was subjected to during loading. It was followed by strain sweep test $\left(\gamma_{0}=0.05-50 \%, \omega=1 \mathrm{~Hz}\right)$. Time sweep test for $10 \mathrm{~min}$ was then performed prior to steady-shear test by varying the shear rate from 0.002 to $100 \mathrm{~s}^{-1}$. Rheological experiments were conducted in triplicate for each sample.

\section{In Vitro Release Testing}

Vertical Franz-type diffusion apparatus (Logan Instruments) maintained at $32 \pm 1^{\circ} \mathrm{C}$ was used to study drug release profile across synthetic membranes (cuprophane membrane and silicone membrane thickness $=0.005 ")$. Two hundred milligrams of the ointment formulation was applied to the mem-

Table III. Firmness and Work of Adhesion Values for the Formulations $(n=3, \pm \mathrm{SD})$

\begin{tabular}{lll}
\hline Formulation & Firmness $(\mathrm{g})$ & Work of adhesion $(\mathrm{g} \mathrm{s})$ \\
\hline HME & $2271.71 \pm 5.30$ & $763.73 \pm 10.50$ \\
Conventional & $2324.81 \pm 8.47$ & $762.37 \pm 32.14$ \\
\hline
\end{tabular}

brane. The receiver compartment consisted of $5 \mathrm{~mL}$ phosphate buffer, $\mathrm{pH}$ 7.4. The active diffusion area of the membrane was $0.50 \mathrm{~cm}^{2}$. During the course of the study, $0.5 \mathrm{~mL}$ of sample was collected from the receiver compartment at various time points and was subsequently replaced with fresh buffer. The collected samples were suitably diluted and analyzed using an HPLC-UV system (Waters Corp) (17-23).

\section{RESULTS AND DISCUSSION}

\section{Preparation of Ointment Formulation Using HME}

Hot-melt extrusion technology is a continuous process of pumping raw materials at high temperature and pressure resulting in a product of uniform shape and density (7). In hot-melt extrusion technology, various process parameters such as feed rate, screw design, screw speed, barrel temperature, and zone of liquid addition have a significant effect on the quality of the final dosage form. All of these parameters were optimized after intensive preliminary studies $(13,14)$. The screw design was modified as shown in Fig. 2, to obtain a uniform product. PEG 3350 and lidocaine $(5 \% \mathrm{w} / \mathrm{w})$ were fed into the barrel via a volumetric feeder. PEG 400, heated equivalent to the extrusion temperature, was injected into the barrel through zone 3 using a peristaltic pump equipped with an injection port. The temperature from zone 2 to zone 5 was set to $75^{\circ} \mathrm{C}$ to ensure complete melting of all the solids before reaching the zone of liquid addition. The first mixing zone helped in the proper mixing of the drug and PEG 3350. After the addition of PEG 400 in zone 3, the mixing zone 2 provided intense mixing action to ensure that all the components are uniformly mixed. The temperature from zone 6 to zone 8 was set to $40^{\circ} \mathrm{C}$. The third mixing zone prevented the formation of agglomerates. The screw speed of $200 \mathrm{rpm}$ was found to be 

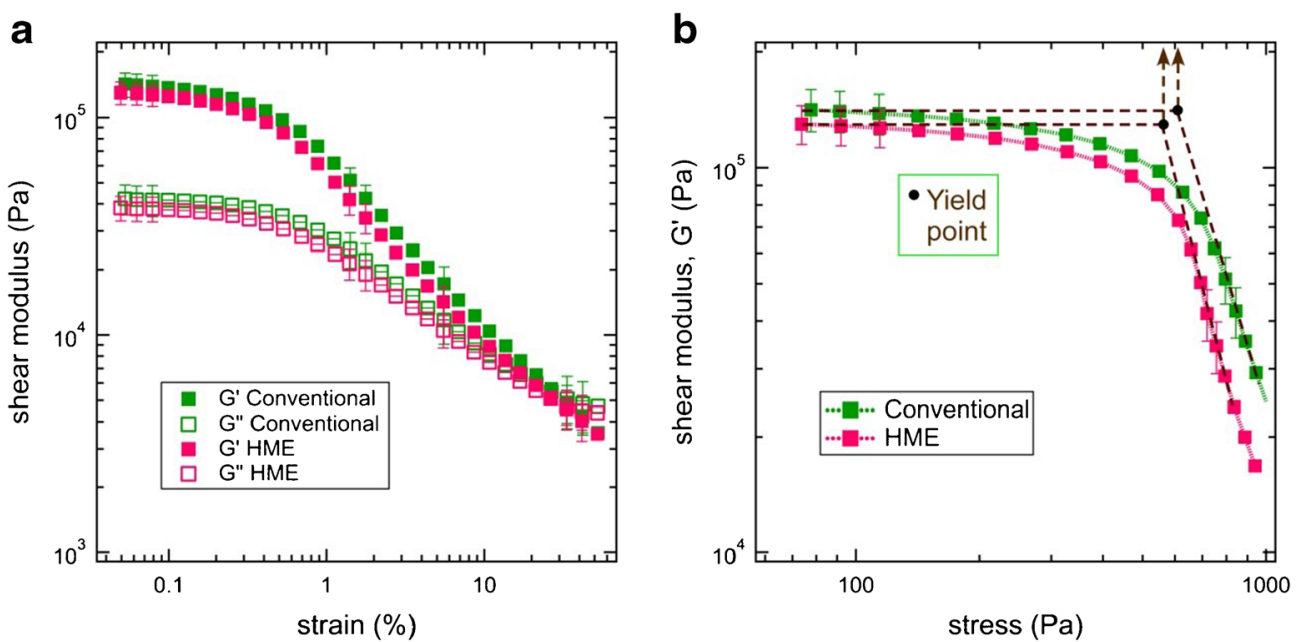

Fig. 6. Rheological characterization: a shear modulus $(\mathrm{Pa})$ versus strain $(\%)$ b shear modulus, $G^{\prime}(\mathrm{Pa})$ versus stress $(\mathrm{Pa})$

optimum for this ointment. During the entire run, the torque values were found to be lower than $2 \%$. The extruded mass gradually cooled down resulting in the final product.

All the formulations were found to be smooth and devoid of any grittiness indicating uniform mixing of contents.

\section{Differential Scanning Calorimetry}

The DSC thermogram shows that pure lidocaine base was characterized by a single endotherm peak representing its melting point at $69^{\circ} \mathrm{C}$ (Fig. 3). PEG 3350 is a semi-crystalline polymer and was found to melt in the range of $60-70^{\circ} \mathrm{C}$. The third component in the formulated ointment is PEG 400, which is a liquid. The DSC thermogram of the placebo ointment (ointment without the drug) shows two peaks, in the temperature range of $40-55^{\circ} \mathrm{C}$ (Fig. 3). The same two peaks are observed in the formulations prepared by HME and conventional process. The absence of drug peak in these two formulations indicates that the crystal morphology of lidocaine is either converted to amorphous nature or it has been solubilized during HME and conventional process.

\section{X-ray Diffraction}

The X-ray diffraction patterns of lidocaine API, placebo (ointment without the drug), HME, and conventional formulations are depicted in Fig. 4. Lidocaine API is a highly crystalline solid and exhibited strong peaks at $2 \theta 10^{\circ}, 12.5^{\circ}$, and $25^{\circ}$. However, diffractograms for both HME and conventional formulations lacked crystalline peaks characteristic for lidocaine and were identical to diffractogram of blank formulation (Fig. 4). This study also suggests that the drug is either present in the amorphous form or has been completely solubilized in the ointment base. To further investigate the nature of drug in the formulation, the solubility of drug in PEG 400 was determined.

\section{Solubility}

In this study, the drug load in the formulation is $5 \% \mathrm{w} / \mathrm{w}$ and the concentration of PEG 400 is $50 \% \mathrm{w} / \mathrm{w}$. Solubility studies revealed that lidocaine is highly soluble in PEG 400
(>250 mg/mL), which is many-fold higher than the concentration of drug in the formulation. Therefore, it is most likely that the drug exists in soluble form in the PEG ointment base.

\section{Uniformity of Drug Content}

As mentioned earlier, uniform mixing of the API with ointment base is one of the challenging tasks in manufacturing of topical semi-solids. Uniformity of drug content indicates the efficiency of mixing process. In this study, we found that the drug content in the hot-melt extruded ointment was 96.56 $\pm 5.21 \%$ and in the conventional ointment was $99.97 \pm 4.36 \%$. It is evident from the results that the modified screw configuration used in this study was effective resulting in a product with uniform drug content.

\section{Formulation pH}

$\mathrm{pH}$ measurement of non aqueous semi-solid bases is a challenge due to lack of compendial recommendations

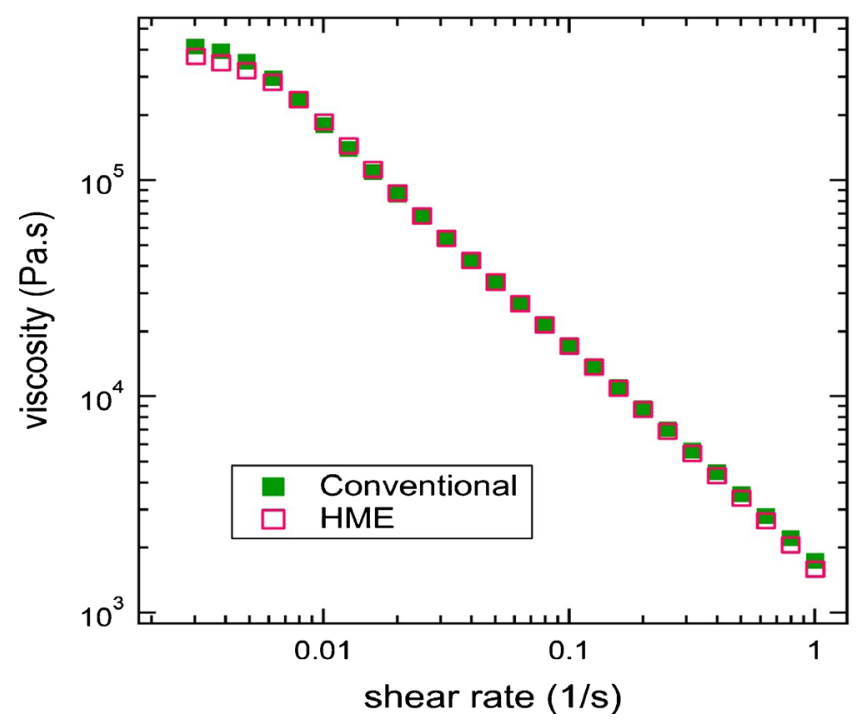

Fig. 7. Plot of viscosity (Pa.s) versus shear rate (1/s) 


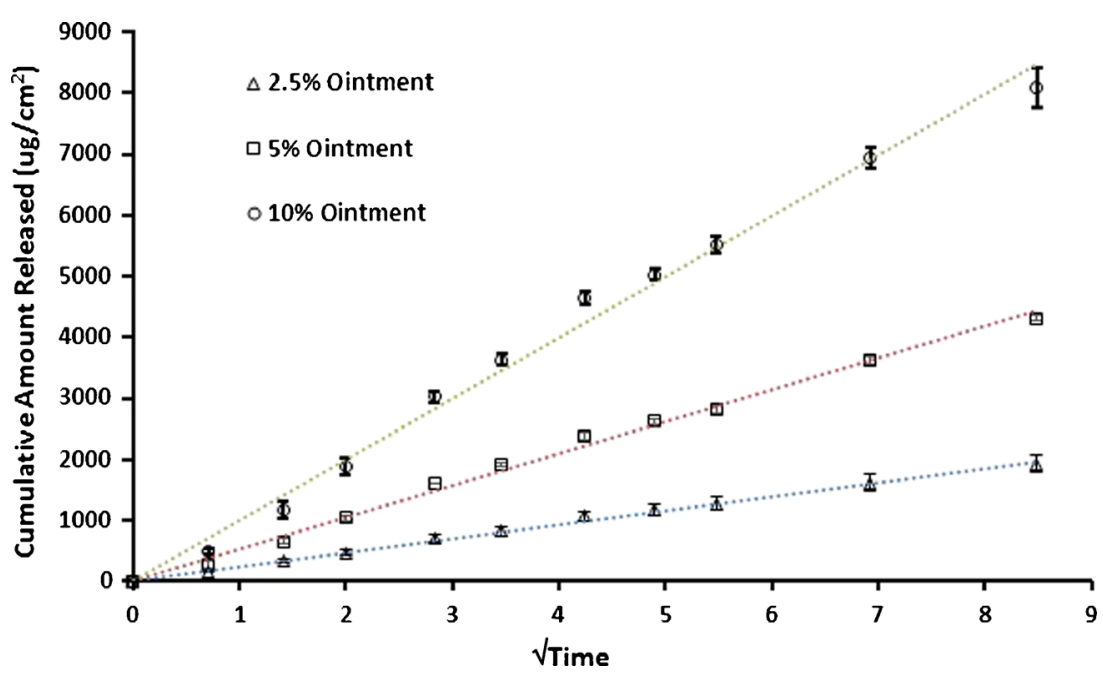

Fig. 8. Plot of cumulative amount released $\left(\mathrm{ug} / \mathrm{cm}^{2}\right)$ versus $\sqrt{ }$ Time for membrane validation studies

$(24,25)$. Therefore, a method was developed to measure the $\mathrm{pH}$ of the ointment. The $\mathrm{pH}$ values $\left(\right.$ at $22^{\circ} \mathrm{C}$ ) for the hot-melt extruded and the conventional formulation were found to be similar, 9.56 \pm 0.19 and 9.31 \pm 0.25 , respectively. Also, it was found that the $\mathrm{pH}$ did not change significantly with incorporation of different amounts of ointment $(1 \% \mathrm{w} / \mathrm{v}, 5 \% \mathrm{w} / \mathrm{v}$, and $10 \% \mathrm{w} / \mathrm{v})$ in water indicating absence of any acidic or alkaline impurities present in the excipients.

\section{Firmness and Work of Adhesion of the Ointment}

Texture parameters such as firmness and work of adhesion of semi-solids are important for product performance as well as for consumer acceptance. Firmness relates to the viscosity of the product and is denoted by the maximum value of force in the plot of force versus time (Fig. 5). The work of adhesion relates to spreadability, and it is the area under the negative portion of the curve delimited by anchor 1 and 2 (Fig. 5). The PEG polymers have a unique property as they add a silky feeling without greasiness to the semi-solid product. The higher firmness and work of adhesion values as shown in Table III indicate that the formulation is viscous and adhesive and thus it finds application as a local anesthetic for the mucous membranes.

\section{Rheology}

Dynamic oscillatory shear and shear flow are common rheological characterization protocol to characterize the stiffness, yield stress, and flow properties of viscoelastic materials, e.g., ointments, creams, and lotions (26). Figure 6a displays storage modulus, $G^{\prime}$, and loss modulus, $G^{\prime \prime}$, as a function of strain amplitude. For low-strain values, the storage modulus is an order of magnitude higher than loss modulus in small strain amplitude which is an indication of a soft solid-like behavior. However, with increasing strain, $G^{\prime}$ starts to decrease, and beyond a strain amplitude $\left(\gamma_{0}\right)$ of greater than $10 \%$, a crossover between $G^{\prime}$ and $G^{\prime \prime}$ has been observed. Further, increasing strain resulted in $G^{\prime \prime}$ become higher than $G^{\prime}$, indicating a more fluid-like behavior.

Rheological results can be used to determine the yield stress of the samples $(27,28)$. The yield stress is defined as the stress required to initiate flow in the ointments, and it is related to the significant change in microstructure of the sam-

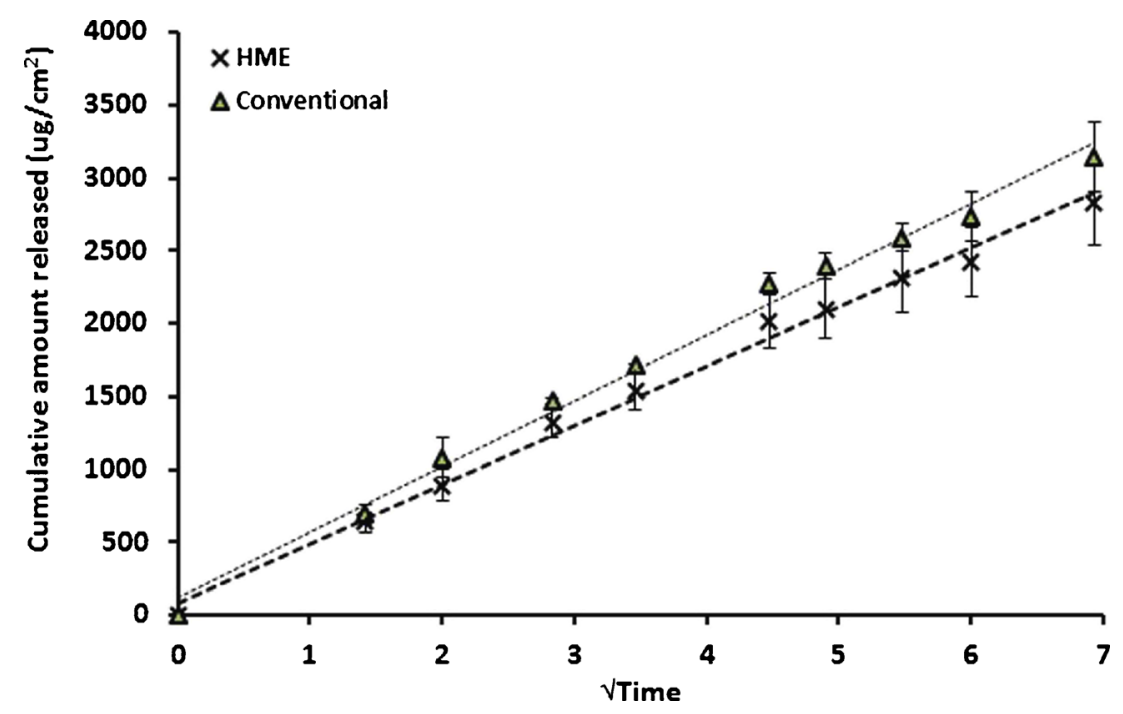

Fig. 9. The in vitro drug release profile of HME and conventional formulation 
ple. To determine yield stress, elastic modulus for different samples was plotted as a function of shear stress in Fig. $6 \mathrm{~b}$. The onset point, the stress in which elastic modulus $\left(G^{\prime}\right)$ declines in a $G^{\prime}$ versus shear stress logarithmic plot, can be determined by applying tangents to the linear and nonlinear regime of the curve. The point where two tangents cross is estimated as the yield stress $\left(\sigma_{\mathrm{Y}}\right)$ of a material. The yield stress for the hot-melt extruded and conventional formulation was found to be $503 \pm 80 \mathrm{~Pa}$ and $570 \pm 70 \mathrm{~Pa}$, respectively. It indicates that the HME and conventional formulations have relatively similar flowing properties. The effect of shear rate on material viscosity has been displayed in Fig. 7. HME and conventional formulations have very similar viscosity profile. As it is observed, apart from the very low shear rate (less than 0.01 ), viscosity decrease with a constant slip for all samples with increasing shear rate. This type of trend is essential in ointments during their use performance to enhance better spreading of a material. The HME and conventional formulations exhibited similar stiffness (elastic modulus, $G^{\prime}$ ) for a similar concentration of polymers.

\section{In Vitro Release Testing}

The use of Franz diffusion cell for in vitro release testing (IVRT) is a simple and reproducible method to evaluate the drug release profile from topical products. However, choosing an appropriate synthetic membrane is often deemed as the most challenging task in IVRT. In the present study, cuprophane membrane was chosen initially for determination of release profile. However, cuprophane being porous and hydrophilic in nature led to penetration of receptor media into the donor compartment owing to osmotic drive. Therefore, a non-porous hydrophobic silicone membrane was selected. To validate this membrane, ointments with different drug loads $(2.5 \% \mathrm{w} / \mathrm{w}, 5 \% \mathrm{w} / \mathrm{w}$, and $10 \% \mathrm{w} / \mathrm{w}$, prepared by the fusion method) were subjected to IVRT. The rate of drug release from the ointment increased with the drug load as shown in Fig. 8, indicating that the membrane was not controlling the rate of drug release. The release profile of the hot-melt extruded and the conventional ointment across silicone membrane was fit to Higuchi kinetic profile, and $K$-value was calculated. The release rate constant (hot-melt extruded ointment, $K=405 \pm 41.59$ and conventional ointment, $K=453.01 \pm 37.40$ ) was not significantly different between the two products (Fig. 9).

\section{CONCLUSION}

The use of HME technology for development of a topical semi-solid product, reported in this study, is the first of its kind. Selection of suitable screw configuration ensures proper mixing of all the components of the formulation in HME. In the present study, the product prepared by HME and conventional processing was similar in terms of rheological properties, drug release profile, and texture characteristics, indicating the efficiency of HME technology to result in a semi-solid product which is similar in quality as that of the reference product. HME technology also provides many advantages over the conventional method of ointment preparation such as minimal processing steps (since melting and mixing is a onestep process), cost effectiveness, uniform product (owing to dispersive and distributive mixing), and shorter processing times. In addition, the different process parameters of HME technology such as feed rate, screw speed, and barrel temperature could be modified to impart desired characteristics to the product.

\section{REFERENCES}

1. "Pharmaceutical Machinery." Ointment Manufacturing Plant, Planetary Mixer, Tube Filling Machine. http:// www.pharmaceuticalmachinery.in/ointment_section.htm. Accessed 14-04-15.

2. "U.S. Food and Drug Administration." Topical Drug Products (7/94). http://www.fda.gov/ICECI/Inspections/InspectionGuides/ ucm074933.htm. Accessed 23-04-15.

3. Patil H, Tiwari RV, Repka MA. Hot melt extrusion: from theory to application in pharmaceutical formulation. AAPS PharmaSciTech. 2015. doi:10.1208/s 12249-015-0360-7.

4. Shah S, Repka MA. Melt extrusion in drug delivery: three decades of progress. In: Repka MA, Langley N, DiNunzio J, editors. Melt extrusion: materials, technology and drug product design. NY: Springer; 2013. p. 4-5.

5. Repka MA, Majumdar S, Battu SK, Srirangam R, Upadhye S. Applications of hot-melt extrusion for drug delivery. Expert Opin Drug Deliv. 2008;5:1357-76.

6. Repka MA, Shah S, Lu J, Maddineni S, Morott J, Patwardhan K, et al. Melt extrusion: process to product. Expert Opin Drug Deliv. 2012;9:105-25.

7. Maniruzzaman M, Boateng JS, Snowden MJ, Douroumis D. A review of hot melt extrusion: process technology to pharmaceutical products. ISRN Pharm. 2012;2012:1-9.

8. Groningsson $\mathrm{K}$, Lindgren JE, Lundberg E, Sandberg R, Wahlen A. Lidocaine base and lidocaine hydrochloride. Analytical profiles of drug substances. New York: Academic; 1985. p. 209-13.

9. http://www.drugbank.ca/drugs/DB00281 Accessed 24-05-15.

10. Fougera ${ }^{\circledR}$ (lidocaine ointment USP, $5 \%$ ) [package insert]. Fougera Pharmaceuticals. Inc. Melville, NY.

11. The pharmaceutics and compounding laboratory. http:// pharmlabs.unc.edu/labs/ointments/bases.htm Accessed 18-04-15.

12. Patil H, Kulkarni V, Majumdar S, Repka MA. Continuous manufacturing of solid lipid nanoparticles by hot melt extrusion. Int J Pharm. 2014;471:153-6.

13. Patil H, Feng X, Ye X, Majumdar S, Repka MA. Continuous production of fenofibrate solid lipid nanoparticles by hot-melt extrusion technology: a systematic study based on a quality by design approach. AAPS J. 2015;17:194-205.

14. Ahmed TA, Ibrahim HM, Ibrahim F, Samy AM, Fetoh E, Nutan MTH. In vitro release, rheological, and stability studies of mefenamic acid coprecipitates in topical formulations. Pharm Dev Technol. 2001;16:497-510.

15. Repka MA, Gutta K, Prodduturi S, Munjal M, Stodghill SP. Characterization of cellulosic hot melt extruded films containing lidocaine. Eur J Pharm Biopharm. 2004;59:189-96.

16. Tai A, Bianchini R, Jachowicz J. Texture analysis of cosmetic/ pharmaceutical raw materials and formulations. Int J Cosmet Sci. 2014;36:291-304.

17. Shah V, Elkins J, Williams R. Evaluation of the test system used for in vitro release of drugs for topical dermatological drug products. Pharm Dev Technol. 1999;4:377-85.

18. Thakker KD, Chern H. Development and validation of in vitro release tests for semisolid dosage forms - case study. Disso Tech. 2003;10:10-5.

19. FDA-SUPAC-SS. Guidance for Industry. SUPAC-SS Nonsterile semisolid dosage forms. Scale-up and postapproval changes: chemistry, manufacturing and controls. In vitro Release Testing and In Vivo Bioequivalence Documentation; 1997. pp. 19-24.

20. Brown MB, Turner R, Lim ST. Topical product formulation development. In: Benson HAE, Watkinson AC, editors. Transdermal and topical drug delivery: principles and practice. Hoboken: Wiley; 2012. p. 255-84.

21. Olejink A, Goscianska J, Nowak I. Active compounds release from semisolid dosage forms. J Pharm Sci. 2012;101:4032-45. 
22. Shah VP, Elkins J, Lam SY, Skelly JP. Determination of in vitro drug release from hydrocortisone creams. Int J Pharm. 1989;53:53-9.

23. Nallagundla S, Patnala S, Kanfer I. Comparison of in vitro release rates of acyclovir from cream formulations using vertical diffusion cells. AAPS PharmaSciTech. 2014;15(4):994-9.

24. Inoue Y, Furuya K, Maeda R, Murata I, Kanamoto I. Assessment of the physical properties and stability of mixtures of tetracycline hydrochloride ointment and acyclovir cream. Int J Pharm. 2013;447:158-64.

25. Ueda CT, Shah VP, Derdzinski K, Ewing G, Flynn G, Maibach H, et al. Topical and transdermal drug products. Pharmacopeial Forum. 2009;35:750-64.
26. Krishnaiah YSR, Xu X, Rahman Z, Yang Y, Katragadda U, Lionberger $\mathrm{R}$, et al. Development of performance matrix for generic product equivalence of acyclovir topical cream. Int $\mathrm{J}$ Pharm. 2014;475:110-22.

27. TA Instruments, Thermal analysis and rheology http:// tainstruments.co.jp/application/pdf/Rheology_Library/ Application_Briefs/RH058.PDF Accessed 13-08-15.

28. Adeyeye MC, Jain AC, Ghorab MKM, Reilly WJ. Viscoelastic evaluation of topical creams containing microcrystalline cellulose/sodium carboxymethyl cellulose as stabilizer. AAPS PharmaSciTech. 2002; 3:(2) article 8:110. 